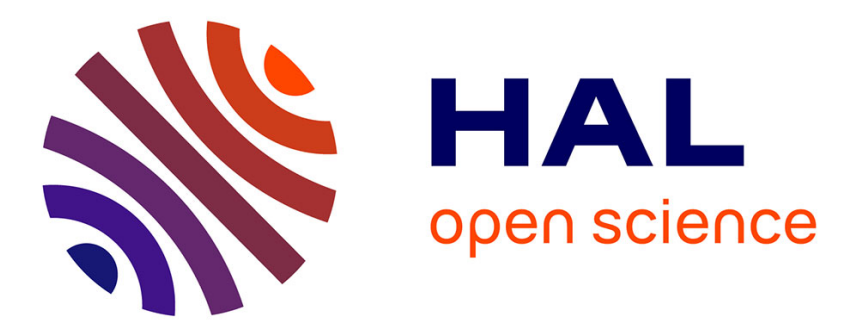

\title{
Rare-earth-free zinc aluminium borate white phosphors for LED lighting
}

P Gaffuri, M. Salaün, I Gautier-Luneau, G Chadeyron, A Potdevin, L Rapenne, E Appert, Vincent Consonni, Alain Ibanez

\section{- To cite this version:}

P Gaffuri, M. Salaün, I Gautier-Luneau, G Chadeyron, A Potdevin, et al.. Rare-earth-free zinc aluminium borate white phosphors for LED lighting. Journal of Materials Chemistry C, 2020, 8 (34), pp.11839-11849. 10.1039/d0tc02196b . hal-02934867

\section{HAL Id: hal-02934867 \\ https://hal.science/hal-02934867}

Submitted on 21 Sep 2020

HAL is a multi-disciplinary open access archive for the deposit and dissemination of scientific research documents, whether they are published or not. The documents may come from teaching and research institutions in France or abroad, or from public or private research centers.
L'archive ouverte pluridisciplinaire HAL, est destinée au dépôt et à la diffusion de documents scientifiques de niveau recherche, publiés ou non, émanant des établissements d'enseignement et de recherche français ou étrangers, des laboratoires publics ou privés. 


\title{
Rare-earth-free zinc aluminium borate white phosphors for LED lighting
}

\author{
P. Gaffuri, ${ }^{a, b}$ M. Salaün, ${ }^{a}$ I. Gautier-Luneau, ${ }^{a}$ G. Chadeyron, ${ }^{c}$ A. Potdevin, ${ }^{c}$ L. Rapenne, ${ }^{b}$ E. \\ Appert, ${ }^{\mathrm{b}}$ V. Consonni, ${ }^{\mathrm{b}}$ A. Ibanez, ${ }^{\mathrm{a}}$
}

\section{FOOTNOTES}

${ }^{\text {a } U n i v . ~ G r e n o b l e ~ A l p e s, ~ C N R S, ~ G r e n o b l e ~ I N P, ~ I n s t i t u t ~ N e ́ e l, ~} 38000$ Grenoble, France.

${ }^{\mathrm{b}}$ Univ. Grenoble Alpes, CNRS, Grenoble INP, LMGP, 38000 Grenoble, France.

${ }^{\mathrm{c}}$ Université Clermont Auvergne, CNRS, SIGMA Clermont, Institut de Chimie de Clermont-Ferrand, F-63000, Clermont-Ferrand, France.

Corresponding author's e-mail: Mathieu.salaun@neel.cnrs.fr

Electronic Supplementary Information (ESI) available.

\begin{abstract}
The use of rare-earth elements (Y, Ce, Eu...) in commercial phosphor-converted white light-emitting diodes (pc-WLEDs) raises environmental and geopolitical concerns. Lanthanide-free white emitting phosphors based on amorphous yttrium aluminium borate (YAB) have previously been synthesized by the polymeric precursor (PP) method, showing high internal quantum yields (iQY) and a broad emission band in the visible range. However, yttrium has still been largely present in the amorphous YAB matrix. Here we synthesize zinc aluminium borate $(\mathrm{ZAB})$ powder by the PP method, a novel family of rare-earth-free phosphor producing broad and intense photoluminescence emissions when excited by near-UV from 300 to $400 \mathrm{~nm}$, with high iQYs up to 60\%. The photoluminescence band is easily tuneable in the visible range of the electromagnetic spectrum, from warm- to cold-white emissions by adjusting either the precursor ratio or the calcination temperature used to prepare the ZAB powders. Finally, we report spectroscopic arguments that reinforce the hypothesis of the molecular origin of the photoluminescence in ZAB phosphors. Our results demonstrate the essential role of the composition ( $\mathrm{Al} / \mathrm{B}$ ratio) and thermal treatment in the transformation and trapping of carbonaceous species (i.e. black carbon or luminescent molecular species) in amorphous ZAB matrix. This efficient family of phosphors only composed of abundant and non-toxic elements opens the way
\end{abstract}


for the integration of rare-earth-free single phosphors synthesized by wet chemistry into WLEDs lighting devices.

\section{INTRODUCTION}

Phosphor-converted white light emitting diodes (pc-WLEDs) have recently dominated the lighting market through their energy efficiency, stability, and ease of integration into smart lighting technologies, thanks to the development of efficient blue- and near-UV (NUV) emitting gallium nitride based LEDs ${ }^{1-3}$ that excite a phosphor to complete the emission and produce white light. The canonical phosphor for LED lighting consists of the $\mathrm{Y}_{3-\mathrm{x}} \mathrm{Ce}_{\mathrm{x}} \mathrm{Al}_{5} \mathrm{O}_{12}$ (YAG:Ce) micron-sized powders emitting around $550 \mathrm{~nm}$, sometimes associated with $\mathrm{Eu}^{2+}$ doped sulphide or nitride to obtain warmwhite emissions. The strong efficiency of YAG:Ce is related to the unique optical properties of $\mathrm{Ce}^{3+}$ ions - i.e. fast optical transition from $5 \mathrm{~d}$ - and $4 \mathrm{f}$-electronic levels - as well as to the good hosting properties of YAG. ${ }^{4,5}$ Nevertheless, the use of rare-earth (RE) elements in such commercial phosphors, as emitter (cerium, europium) and host matrix (yttrium), raises environmental and geopolitical concerns. ${ }^{6,7}$ Thus, efficient RE-free single phosphors, excitable in the blue / NUV range and exhibiting a broad emission band extended in the whole visible range, are strategic materials to be developed, although it remains a major scientific challenge. ${ }^{8,9}$

On one hand, a tremendous effort has been devoted to the identification of a suitable WLED phosphor matrix to host RE ions, ${ }^{10-13}$ including RE-free matrix, which decreases the overall RE content in phosphors, yet does not remove them completely. On the other hand, phosphors based on a RE-free photoluminescence (PL) have extensively been studied. Among them, defect-related luminescent materials, synthesized by chemical methods, are good candidates since they typically combine high PL efficiency, good stability, ease of fabrication, as well as a broad PL emission. ${ }^{14}$ Pioneering works on these materials were done on silicate-based matrices, ${ }^{15,16}$ which now includes phosphates, ${ }^{17,18}$ metal oxides, ${ }^{19-25}$ boron carbon oxynitride (BCNO), ${ }^{26-28}$ and carbon-based nanomaterials. ${ }^{29}$ These phosphors are promising, although they generally produce blue or bluish-white light, their quantum efficiencies are not systematically specified, and their PL mechanisms are not fully understood. 
Recently, amorphous yttrium aluminium borate (YAB) have been synthesized by the polymeric precursor (PP) method, showing high internal quantum yields (iQY) and a warm-white emission. ${ }^{30,31}$ Amorphous YAB was also synthesized by the sol-gel method, where the emission of polycyclic aromatic hydrocarbon molecules, trapped in the amorphous matrix during the synthesis process of the micron-sized powders, was for the first time evidenced by coupling thermal analyses (differential thermal analysis, thermogravimetry, mass spectrometry), PL spectroscopy, nuclear magnetic resonance and electron paramagnetic resonance measurements coupled with DFT calculations. ${ }^{32}$ Nevertheless, yttrium was still used in significant amounts to form the glassy aluminium borate matrix, acting as a cation glass network modifier.

In this article, we present a novel matrix of RE-free phosphor made of zinc aluminium borate (ZAB) synthesized by the PP method. The content of zinc, aluminium, and boron is varied, along with the thermal treatment conditions, in order to elucidate their effects on the morphology, the microstructure and the trapping of black carbon and molecular PL emitters in the ZAB network. The corresponding evolution of the PL properties are thoroughly analysed, also by varying the excitation wavelength, to provide spectroscopic insights into the origin of the luminescence in ZAB phosphors.

\section{EXPERIMENTAL}

\section{Synthesis method}

The preparation of ZAB powders was based on the PP methods, also labelled as modified Pechini methods. ${ }^{30} \mathrm{Zn}\left(\mathrm{NO}_{3}\right)_{2} \cdot 6 \mathrm{H}_{2} \mathrm{O}$ (1 g, 99\%, Alpha Aesar), $\mathrm{Al}\left(\mathrm{NO}_{3}\right)_{3} \cdot 9 \mathrm{H}_{2} \mathrm{O}$ (3.85 to $9.4 \mathrm{~g}, 99 \%$, Fisher Scientific) and citric acid monohydrate (32 g, Fisher Scientific) were dissolved in $50 \mathrm{~mL}$ of ultrapure water $\left(0.63 \mu \mathrm{S} / \mathrm{cm}\right.$, Fisher Scientific) heated at $80^{\circ} \mathrm{C}$ under stirring for $15 \mathrm{~min}$. Simultaneously, in a second solution, $\mathrm{H}_{3} \mathrm{BO}_{3}$ (1.20 to $2.46 \mathrm{~g}$, 99.8\%, Fisher Scientific) and D-sorbitol (20 g, Fisher Scientific) were dissolved in $50 \mathrm{~mL}$ of ultrapure water heated at $80^{\circ} \mathrm{C}$ under stirring for $15 \mathrm{~min}$. This polyalcohol has been chosen instead of conventional ethylene glycol to improve boron complexation, thus avoiding boron losses during thermal annealings. ${ }^{33,34}$ The $\mathrm{Al} / \mathrm{B}$ molar ratio between aluminium and boron precursors were set to $0.25,0.5,0.75$ and 1.5 , while the molar ratio between all inorganic 
precursors ( $\mathrm{Zn}, \mathrm{Al}$ and $\mathrm{B})$ and citric acid was kept at 1:3. The two solutions were then mixed together and heated under reflux at $100{ }^{\circ} \mathrm{C}$ for 44 hours. The solution was partially evaporated at $80{ }^{\circ} \mathrm{C}$ to promote the esterification reactions, leading to a yellowish and viscous resin, which was further dried at $250{ }^{\circ} \mathrm{C}$ during $30 \mathrm{~min}$, under air atmosphere. The resulting dried resin was crushed in a planetary mill to obtain fine brown powders, then pyrolysed under $\mathrm{N}_{2}$ continuous flux at $700^{\circ} \mathrm{C}$ during 24 hours, releasing a large amount of organic moieties through mainly $\mathrm{CO}_{2}$ and $\mathrm{H}_{2} \mathrm{O}$ losses related to citrate groups decomposition ${ }^{35}$ without any drastic combustion reactions. Pyrolysed powders were subsequently sieved with a $20 \mu \mathrm{m}$ stainless steel mesh. Finally, grains with size under $20 \mu \mathrm{m}$ powders were calcinated at different temperatures ranging from 600 to $1000{ }^{\circ} \mathrm{C}$ for 24 hours under $\mathrm{O}_{2}$, forming the ZAB particles.

\section{Microstructural characterizations}

The morphology of ZAB particles was observed in a field emission scanning electron microscope (FESEM) ZEISS Ultra+ operating with an acceleration voltage $\mathrm{V}=20 \mathrm{kV}$. Analysis of the chemical composition was carried out on the FESEM equipped with a Bruker EDS system with a Silicon Drift Detector. Transmission electron microscopy (TEM) and scanning transmission electron microscopy (STEM) specimens were prepared by depositing a drop of ZAB powders dispersed in absolute ethanol, onto carbon grids. The surface of the particles was investigated by TEM with a JEOL-JEM 2010 microscope operating at $200 \mathrm{kV}$ with a $0.19 \mathrm{~nm}$ point to point resolution. The chemical homogeneity was assessed with STEM-EDS elemental maps of single particles that were collected with a JEOL SDD Centurio detector having a large solid angle of up to 0.98 steradians incorporated in the JEOL 2100F field-emission-gun scanning electron microscope operating at $200 \mathrm{kV}$ and having a $0.2 \mathrm{~nm}$ resolution in the scanning mode.

In situ temperature-dependent powder X-ray diffraction (PXRD) was used to record the structural changes occurring during the calcination step. The powder was dispersed on an alumina crucible placed at the focal point of the X-ray $(\mathrm{Cu} \mathrm{K \alpha 1)}$ incident beam. Diffracted X-rays were recorded from $20^{\circ}$ to $120^{\circ}$ in $2 \theta$, under air, from room temperature to $900{ }^{\circ} \mathrm{C}$ with a heating rate of $1{ }^{\circ} \mathrm{C} / \mathrm{min}$. Room- 
temperature PXRD patterns were collected with a Brucker D8 Endeavour diffractometer using $\mathrm{Cu}$

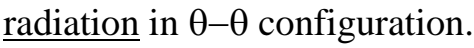

\section{Optical characterizations}

The optical properties were investigated by recording the PL spectra with a Jobin-Yvon set-up consisting of a Xenon lamp operating at $400 \mathrm{~W}$ and two monochromators (Triax 550 and Triax 180) combined with a cryogenically cold charge coupled device (CCD) camera (Jobin-Yvon Symphony LN2 series) for emission spectra $\left(\lambda_{\text {exc }}=385 \mathrm{~nm}\right)$ and with a Hamamatsu 980 photomultiplicator for excitation ones. iQY efficiencies and absorbance were recorded using C9920-02G PL-QY measurement system from Hamamatsu. The setup comprised a 150W monochromatized Xe lamp, an integrating sphere (Spectralon Coating, $\varnothing=3.3$ inch) and a high sensitivity CCD spectrometer for detecting the whole spectral luminescence. Trichromatic coordinates were also determined thanks to this equipment. All luminescence experiments were performed at room temperature.

\section{RESULTS AND DISCUSSION}

\section{Powder synthesis}

ZAB phosphors were synthesized by the PP method, which is suitable to form multi-metal oxides with a high homogeneity at the molecular level. ${ }^{36}$ This method has previously been used to synthesize YAB particles having a strong and broad PL band in the visible range when excited from 250 to 400 nm. ${ }^{30,31,35}$ In order to synthesize RE-free phosphors, yttrium should be substituted from the composition, but without major modification of the amorphous structure. Zinc was selected to substitute yttrium, as their field strengths (i.e. the charge divided by the square of the radius) of 0.52 and 0.53 , respectively, are similar ${ }^{37,38}$. As a result, both cations belong to the category of glass network modifier, according to Dietzel theory. ${ }^{39}$ Moreover, $\mathrm{Zn}^{2+}\left(3 \mathrm{~d}^{10}\right)$ ions as well as $\mathrm{Y}^{3+}\left(4 \mathrm{~d}^{0}\right)$ ions do not give rise to any absorption in the NUV and visible region.

The powders with the strongest PL were obtained with a Al / B precursor molar ratios of $0.25,0.5$, and $\underline{0.75}$ and a constant $\mathrm{ZnO}$ molar ratio of $12 \%$. Photographs of those three optimized $\mathrm{ZAB}$ powders under daylight illumination and under $365 \mathrm{~nm}$ excitation are shown in Fig. 1a and 1b, respectively, as 
a function of the calcination temperature $\left(\mathrm{T}_{\mathrm{Ca}}\right)$ ranging from 600 to $750^{\circ} \mathrm{C}$. Before the calcination step, the black colour of carbon-rich pyrolysed powder is attributed to the presence of black carbon arising from the decomposition of organic precursors, as confirmed by the typical Raman bands of such disordered carbon shown in Fig. S1..$^{40-42}$ Accordingly, the brown colour under daylight illumination of powders calcined with low $\mathrm{T}_{\mathrm{Ca}}$ is attributed to the remaining of small clusters of black carbon formed during the pyrolysis step. ${ }_{-}^{36}$ When $\mathrm{T}_{\mathrm{Ca}}$ is raised, this trapped black carbon is further oxidized and released as $\mathrm{CO}_{2}$ gas, as shown by thermogravimetric analysis (TGA) coupled with differential thermal analysis (DTA) and mass spectrometry (MS) (Fig. S2), as well as SEM-EDS (Fig. S3), leading to the whitening of the powder. Interestingly, the whitening if the powder occurs at a lower $\mathrm{T}_{\mathrm{Ca}}$ when the $\mathrm{Al} /$ $\underline{B}$ ratio is increased. Indeed, as shown in Fig. S2, the mass ratio of carbon in calcinated ZAB powder at $600^{\circ} \mathrm{C}$ is less than $1 \%, 5 \%$, and $20 \%$ for $\mathrm{Al} / \mathrm{B}$ ratios of $0.75,0.5$ and 0.25 , respectively, evidencing the lower carbon trapping of the matrix when the $\mathrm{Al} / \mathrm{B}$ ratio is increased.
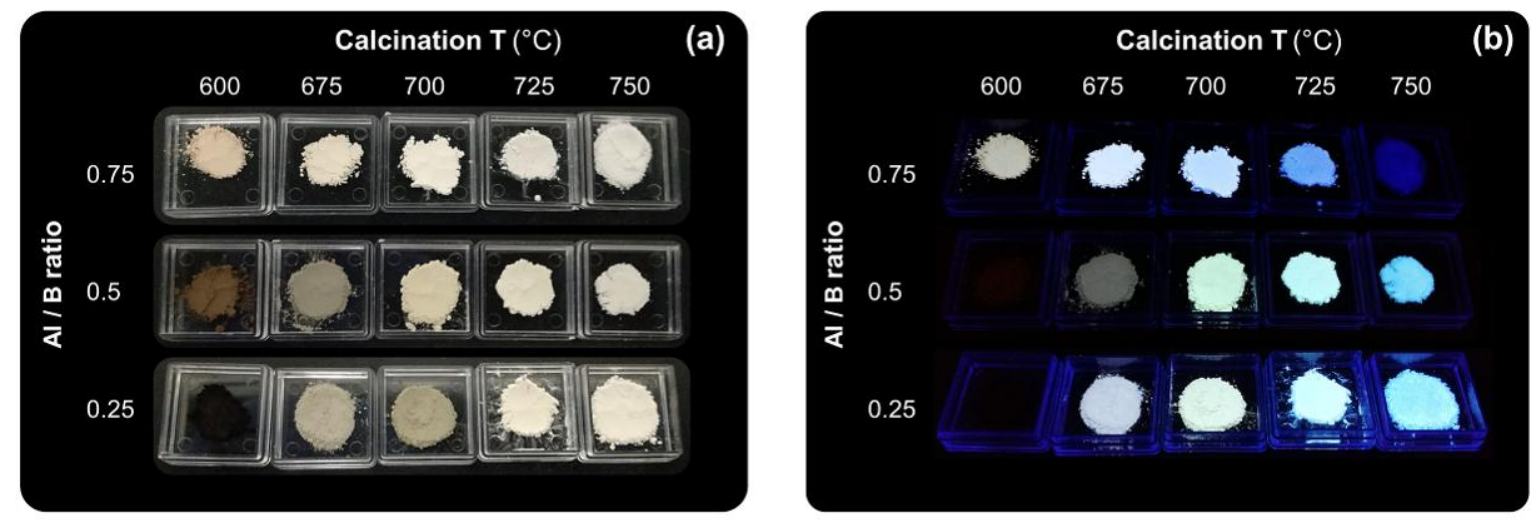

Fig. 1 (a) Photographs of the optimized ZAB phosphor powders, under daylight and (b) under NUV illumination at $365 \mathrm{~nm}$.

Similarly, the luminescence is strongly affected by $\mathrm{T}_{\mathrm{Ca}}$. No PL emission occurs with the naked eye in the ZAB particles calcinated at a low temperature (Fig. 1b), due to the large amount of black carbon they contain and which absorbs all lights. Increasing the $\mathrm{T}_{\mathrm{Ca}}$ leads to a warmer PL under NUV, particularly for $\mathrm{Al} / \mathrm{B}$ ratios of 0.25 and 0.5 , which is blue shifted by further raising the $\mathrm{T}_{\mathrm{Ca}}$, regardless of the $\mathrm{Al} / \mathrm{B}$ ratio of the $\mathrm{ZAB}$ particles. Finally, the $\mathrm{ZAB}$ powders lose their PL properties for a $\mathrm{T}_{\mathrm{Ca}}$ comprised between 750 and $800{ }^{\circ} \mathrm{C}$ (Fig. S4). Hence, there is an optimum $\mathrm{T}_{\mathrm{Ca}}$ range, at which the ZAB powders possess strong PL properties and the suitable warm-white emission. 
The chemical purity of the three optimized powders was assessed by SEM-EDS, as shown in Fig. S5a where the absence of peaks related to other chemical elements in the EDS spectra is clearly shown, considering the high electron acceleration voltage of $20 \mathrm{kV}$. The inset shows an enlargement of the SEM-EDS spectra normalized with respect to the oxygen peak. The good match between the decrease in the $\mathrm{Al} / \mathrm{B}$ precursor ratios and the decrease in the intensity of the $\mathrm{Al} \mathrm{K} \alpha$ peak shows the successful adjustment of the composition of the final oxide particles.

Finally, in addition to the optimized compositions, Fig. S5b shows the other chemical compositions tested which are very weakly or not luminescent (as observed in Fig. S4), due to the formation of crystallized solids, as specified in the following paragraph on particle microstructure.

\section{Particle morphology}

The morphology of the ZAB particles is shown in the FESEM micrograph in Fig. 2a. A representative particle with a $\mathrm{Al} / \mathrm{B}$ ratio of 0.75 and $\mathrm{T}_{\mathrm{Ca}}$ of $675{ }^{\circ} \mathrm{C}$ presents a smooth surface and conchoidal fractures (Fig. 2b) characteristic of a glassy structure, as previously observed in YAB phosphors. ${ }^{43} \mathrm{On}$ the other hand, a typical particle with $\mathrm{Al} / \mathrm{B}$ ratio of 0.25 also calcinated at $675{ }^{\circ} \mathrm{C}$ has a rough surface (Fig. 2c). Indeed, the surface of such particles was observed at higher magnification by TEM, showing a thin shell of crystalline nanowires indexed as phase similar to $\mathrm{Al}_{2} \underline{B}_{2} \underline{O}_{2}{ }_{2}{ }^{44}$ as shown in Fig. $2 \mathrm{~d}, 2 \mathrm{e}$, and S6. These surface differences between Al-rich and B-rich particles are highlighted for a $\mathrm{T}_{\mathrm{Ca}}$ of $700^{\circ} \mathrm{C}$ in Fig. S7, while varying the chemical composition had no significant effect on particle size. Finally, raising $\mathrm{T}_{\mathrm{Ca}}$ to $1000^{\circ} \mathrm{C}$ leads to the formation of entangled non-luminescent whiskers for all $\mathrm{Al} / \mathrm{B}$ ratios (Fig. S8 and S4) due to deep particle crystallization at very high $\mathrm{T}_{\mathrm{Ca}}$. 

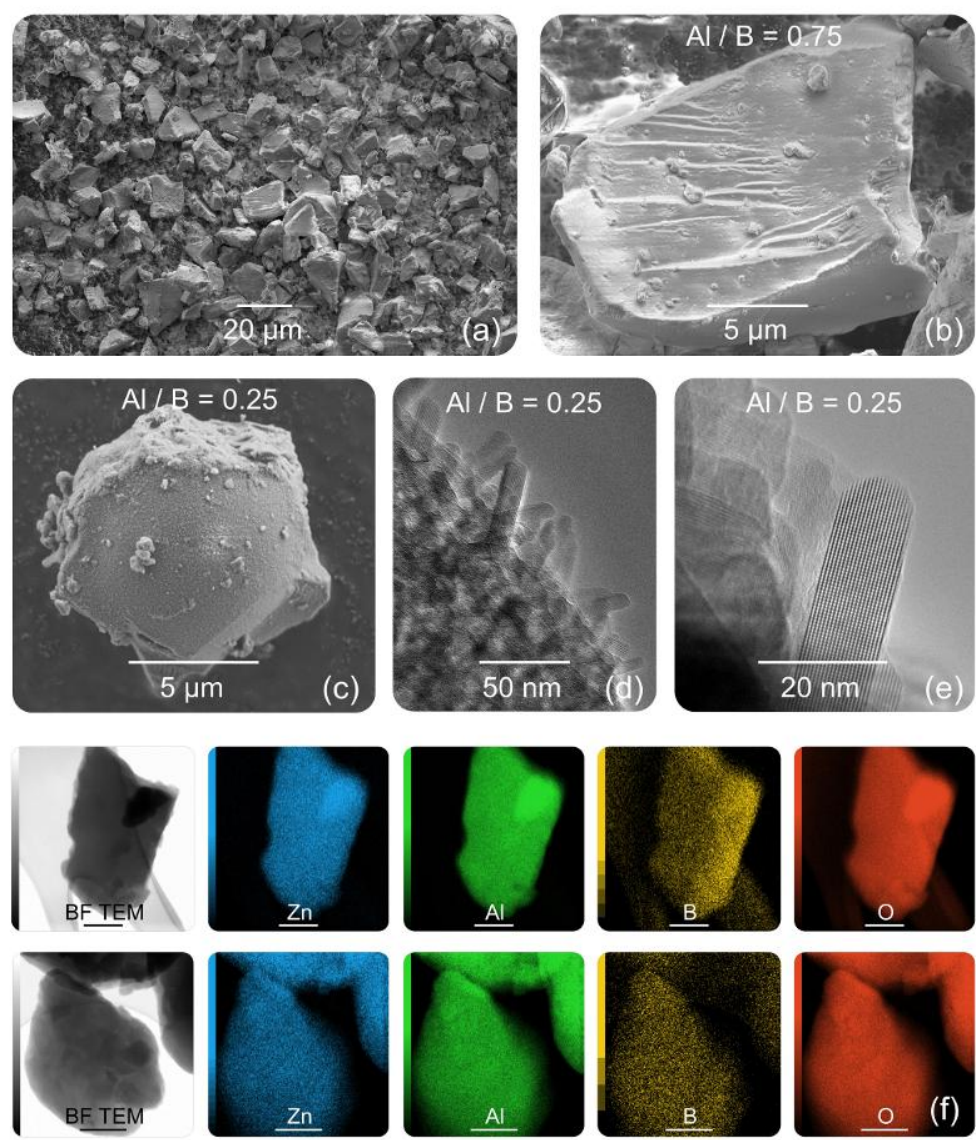

Fig. 2 FESEM micrographs showing (a) a global view of ZAB particles, and single ZAB particles (b) with $\mathrm{Al} / \mathrm{B}=0.75$ and $(\boldsymbol{c})$ with $\mathrm{Al} / \mathrm{B}=0.25$. (d-e) Bright-field TEM micrographs of the surface of particles with $A l / B=0.25$. (f) STEM-EDS elemental maps of ZAB luminescent particles, here for $A l /$ $\underline{B=0.75, \text { and } T_{C a}=650^{\circ} \mathrm{C} \text {, showing their good chemical homogeneity. The scale bars are } 250 \mathrm{~nm} .}$

EDS elemental maps of glassy ZAB particles calcinated at $\mathrm{T}_{\mathrm{Ca}}=650{ }^{\circ} \mathrm{C}$ (i.e. below their crystallization temperature, see next section) were collected by STEM (see Fig. 2f). No element is shown to be segregated, unlike similar AlBCNO white emitting phosphors. ${ }^{45}$ The more intense regions of the elemental maps are only due to larger probed area in overlapping particles, as shown in the bright-field image. Indeed, the poly-esterification reactions between $\mathrm{Al}$ and $\mathrm{Zn}$ citrates complexes and the alcoholate boron ones during the first step of the synthesis avoid the segregation of the metal cations during the formation of the oxide network, promoting in turn its high molecular homogeneity.

\section{Particle microstructure}

As the exothermic peaks observed in TGA-DTA analyses (Fig. S2) can both be attributed to the crystallization of ZAB powders, and to the calcination of the residual carbonaceous species, the 
crystallization behaviour of the powders with $\mathrm{Al} / \mathrm{B}$ ratios of 0.75 and 0.25 was assessed by in situ temperature-dependent XRD (Fig. 3). Besides, contrary to our previous work carried out on YAB vitreous powders,${ }^{30}$ we could not clearly identify in this study the glassy transition for ZAB samples on the DTA curves.

Two broad bands of X-ray scattering centred around $2 \theta=25^{\circ}$ and $45^{\circ}$ that are characteristic of the amorphous structure turn into diffraction peaks within a few degrees at around $660{ }^{\circ} \mathrm{C}$ for both $\mathrm{Al} / \mathrm{B}$ ratios of 0.25 and 0.5 (Fig. S9). In contrast, for the $\mathrm{Al} / \mathrm{B}$ ratio of 0.75 , the crystallization into the same crystallographic phase is delayed to $775{ }^{\circ} \mathrm{C}$, showing the significant effect of the $\mathrm{Al} / \mathrm{B}$ ratio on the amorphous matrix, between $\mathrm{Al} / \mathrm{B}$ ratio of 0.5 and 0.75 . It has been reported in the literature that increasing the $\mathrm{Al}$ content in borate glasses leads to a higher $\mathrm{T}_{\mathrm{g}}$ and a decrease in the atomic packing density. This is attributed to an increase of the coordination number of $\mathrm{Al}$ from 4 to 5 and $6,{ }^{46,47}$ observed by solid-state NMR when the $\mathrm{Al}$ molar ratio exceed $30 \%,{ }^{48}$ i.e. when $\mathrm{Al} / \mathrm{B}>0.5$ in our case. The increase in $T_{g}$ should account for the increase in crystallization temperature, while the atomic packing density affects the release of carbonaceous moieties from ZAB particles. Indeed, we believe that the larger content of carbon measured in boron-rich particles is due to a denser packing of the amorphous network, thus trapping the carbonaceous species more efficiently during the calcination process. It is remarkable that microstructural considerations in melt-quenched glasses seem to apply to amorphous grains obtained by the PP method. 


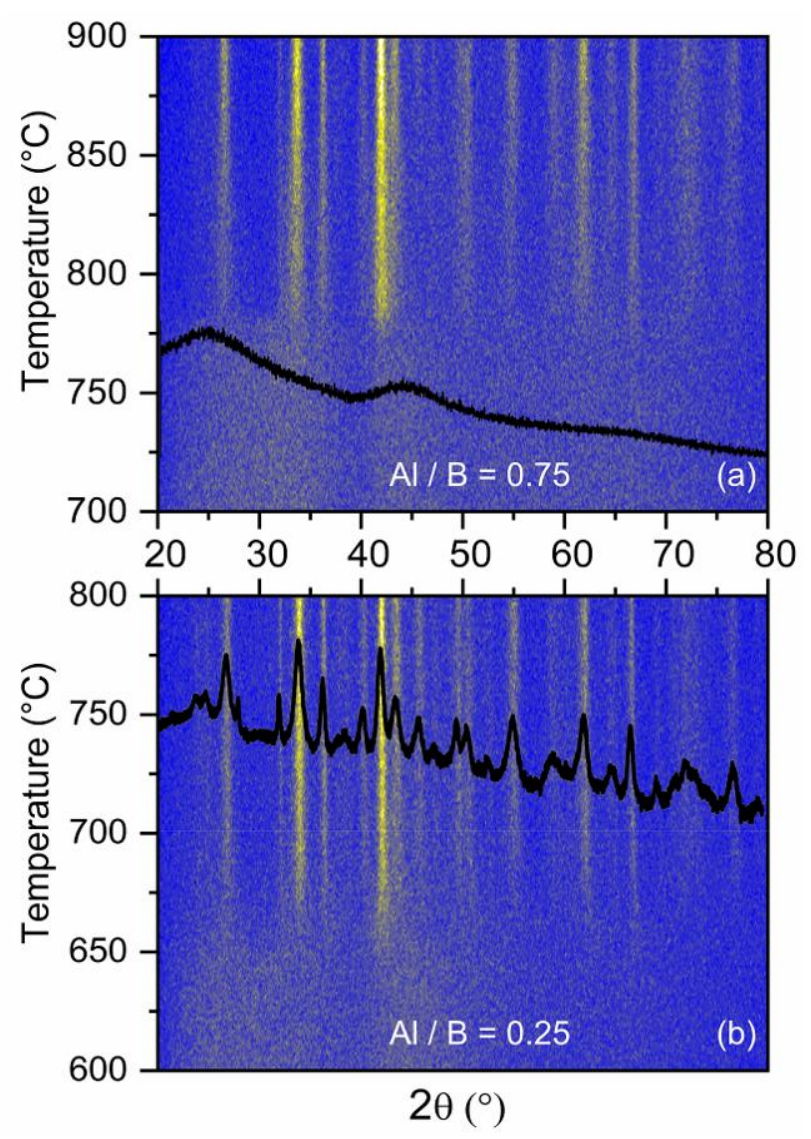

Fig. 3 In situ temperature-dependent PXRD diffractogram of ZAB particles (previously pyrolysed) calcinated under air for the compositions (a) $A l / B=0.75$ and (b) $A l / B=0.25$. To highlight the scattering bands and diffraction peaks, and to overcome the low instrumental counts bellow $2 \theta=25^{\circ}$, conventional room-temperature diffractograms of ZAB powder with corresponding $\mathrm{Al} / \mathrm{B}$ ratio, calcinated at $750^{\circ} \mathrm{C}$, have been superimposed. The diffractogram shown in (b) is indexed in Fig. S10.

In order to identify the resulting crystalline phases, PXRD patterns were registered. The crystallographic phase could not be found in any databases, yet it showed similarities with that of $\mathrm{Al}_{4} \mathrm{~B}_{2} \mathrm{O}_{9}$ together with those of $\mathrm{Cu}_{2} \mathrm{Al}_{6} \mathrm{~B}_{4} \mathrm{O}_{17}$ or $\mathrm{LiAl}_{7} \mathrm{~B}_{4} \mathrm{O}_{17}$ (see Powder Diffraction Files 00-0290010, 04-15-3532 and 00-052-1131 respectively), ${ }^{49,50}$ as shown in Fig. S10, suggesting a zinc aluminium borate phase. Similarly, the first phase to crystalize in $\mathrm{YAB}$ phosphors is $\mathrm{Al}_{4} \underline{B}_{2} \underline{\mathrm{O}}_{2}{ }_{2}{ }^{\underline{30}}$ Very interestingly, the formation of $\mathrm{Cu}_{2} \mathrm{Al}_{6} \mathrm{~B}_{4} \mathrm{O}_{17}$ whiskers nucleating from the surface of aluminium borate particles, before growing as independent micrometric whiskers at higher temperature, has been reported previously, ${ }^{49}$ similarly to ZAB particles in Fig. S8. Nevertheless, the strong PL of fully amorphous aluminium-rich ZAB phosphors, together with the absence of luminescence in powders 
calcinated from 800 to $1000^{\circ} \mathrm{C}$ (Fig. S4), rich in the crystalline phase, rules out the hypothesis of luminescent crystalline phase.

The FESEM and TEM micrographs, together with the analogy with the $\mathrm{Cu}_{2} \mathrm{Al}_{6} \mathrm{~B}_{4} \mathrm{O}_{17}$ phase clearly indicates that only the surface of boron-rich luminescent ZAB particles crystallizes at $660{ }^{\circ} \mathrm{C}$, leaving a large amorphous core where carbonaceous species are trapped. Inversely, the composition leading to non-luminescent powders (Fig. S4) are characterized by a strong crystallization. Indeed, an increase in the $\mathrm{ZnO}$ content from $12 \%$ to $20 \%$ led to sharp peaks corresponding to $\mathrm{ZnB}_{4} \underline{\mathrm{O}}_{7}$ in addition to the previous metal aluminium borate phase (Fig. S11), and the removal of Al led to sharp peaks corresponding to $\mathrm{ZnB}_{4} \underline{\mathrm{O}}_{7}$ as well as $\mathrm{B}(\mathrm{OH})_{3}$ (Fig. S12). We correlate this crystallization and phase segregation with their non-luminescence due to the loss of molecular emitters during the complete crystallization of the matrix, as observed in $\mathrm{ZAB}$ and previously in $\mathrm{YAB}^{30,35}$ phosphors, when the $\mathrm{T}_{\mathrm{Ca}}$ is above $800^{\circ} \mathrm{C}$ (Fig. S4). These observations show that the presence of a large majority of amorphous phase in ZAB phosphors through an optimized metallic precursor ratio is necessary for their $\underline{\text { luminescence properties. }}$

\section{Photoluminescence properties of ZAB phosphors}

In the first part of the article, we showed that $\mathrm{Al} / \mathrm{B}$ ratios of 0.5 and 0.25 led to similar structural properties in $\mathrm{ZAB}$ powders. The rest of the article will focus on $\mathrm{Al} / \mathrm{B}=0.5$, leaving the very similar $\mathrm{Al} / \mathrm{B}=0.25$ in the supporting information, to highlight the critical effect of the composition between $\mathrm{Al} / \mathrm{B}=0.75$ and 0.5 on the PL properties of ZAB phosphors.

Fig. 4 shows the room-temperature emission spectra of ZAB particles under NUV excitation at $385 \mathrm{~nm}$, which corresponds to the typical emission wavelength of some commercial NUV LEDs. This analysis hence allows us to estimate the potential of these phosphors for their application as single white phosphors in NUV LED-based devices. 

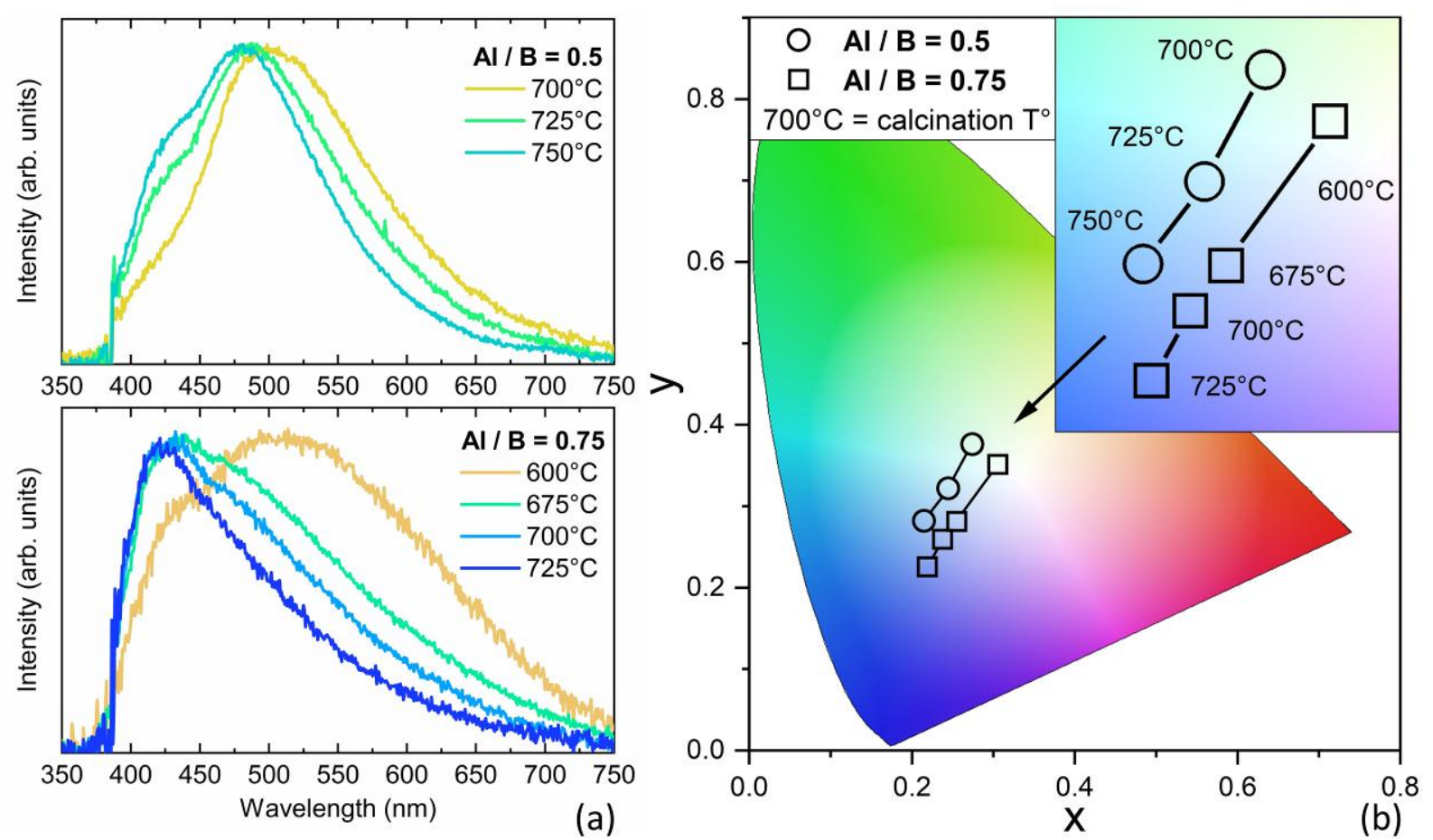

Fig. 4 (a) Normalized room-temperature PL spectra and (b) chromaticity (CIE 1931) of the ZAB particles excited at $385 \mathrm{~nm}$, for $\mathrm{Al} / \mathrm{B}=0.5$ and 0.75 , with $T_{C a}$ ranging from $600{ }^{\circ} \mathrm{C}$ to $725^{\circ} \mathrm{C}$ and 700 ${ }^{\circ} \mathrm{C}$ to $750{ }^{\circ} \mathrm{C}$, respectively.

The normalized room-temperature PL spectra of ZAB phosphors with $\mathrm{Al} / \mathrm{B}$ ratios of $0.25,0.5$, and 0.75 are shown in Fig. S13 and Fig. 4a. For all compositions, a broad emission band is observed from 400 to $700 \mathrm{~nm}$ which blue shifts by raising $\mathrm{T}_{\mathrm{Ca}}$. In the case of the $\mathrm{Al} / \mathrm{B}$ ratio of 0.5 , the PL spectra are centred at $500 \mathrm{~nm}$, and by raising $\mathrm{T}_{\mathrm{Ca}}$, the warm colour contribution from 550 to $700 \mathrm{~nm}$ decreases in favour of shorter wavelengths from 400 to $450 \mathrm{~nm}$. For the $\mathrm{Al} / \mathrm{B}$ ratio of 0.75 , the $\mathrm{PL}$ emission is extended in the whole visible wavelengths for $\mathrm{T}_{\mathrm{Ca}}=600{ }^{\circ} \mathrm{C}$, while it gradually narrows towards shorter wavelengths $(400-550 \mathrm{~nm})$ when $\mathrm{T}_{\mathrm{Ca}}$ is raised from $675^{\circ} \mathrm{C}$ to $725^{\circ} \mathrm{C}$. Finally, the PL spectra and the variation with respect to $\mathrm{T}_{\mathrm{Ca}}$ are very similar for phosphors with the $\mathrm{Al} / \mathrm{B}$ ratios of 0.25 and 0.5, as seen in Fig. S13.

The corresponding colour points of ZAB phosphors are depicted in Fig. $4 \mathrm{~b}$ in a standard twodimensional CIE 1931 chromaticity diagram. As expected, the distribution of emitted photons from ZAB phosphors excited at $385 \mathrm{~nm}$ changes from white (pure white being located at $\mathrm{x}=\mathrm{y}=0.33$ ) to bluish emission with increasing $\mathrm{T}_{\mathrm{Ca}}$. This blue shift contrasts with the $\mathrm{YAB}$ phosphors synthesized by 
the PP method as well as by the sol-gel process, where a red shift of the emission band has commonly been observed by raising $\mathrm{T}_{\mathrm{Ca}}{ }^{30-32}$. This can be first attributed to the different role of $\mathrm{Zn}$ comparing to $\mathrm{Y}$ in the formation and structure of the amorphous network, thus trapping different molecular emitters. Moreover, ZAB particles have a significantly lower diameter and size distribution than YAB phosphors (diameters from 30 to $70 \mu \mathrm{m}$ ) due to the sieving of pyrolysed particle with a $20 \mu \mathrm{m}$ mesh, which strongly affects particle formation, as well as the oxidation of carbonaceous species during the calcination step. Finally it should be noted here that the PL of ZAB phosphors with the highest $\mathrm{Al} / \mathrm{B}$ ratio of 0.75 shifts at a significantly lower $\mathrm{T}_{\mathrm{Ca}}$ than for the other two, similarly to the carbon content (Fig. S2).

The PL iQY, absorbance (Abs) and external quantum yields (eQY) of the most luminescent ZAB phosphors are shown in Fig.5, and correspond to the following formulae: ${ }^{51}$

$\mathrm{iQY}=\frac{\text { number of } p \square \text { otons emitted }}{\text { number of } p \square \text { otons absorbed }}$
$\mathrm{Abs}=\frac{\text { number of } p \square \text { otons absorbed }}{\text { number of incident } p \square \text { otons }}$
$\mathrm{eQY}=\mathrm{iQY} \times$ Abs $=\frac{\text { number of } p \square \text { otons emitted }}{\text { number of incident } p \square \text { otons }}$

$\lambda_{\text {exc }}$ was set to $385 \mathrm{~nm}$, but also to $305 \mathrm{~nm}$, because the excitation-dependent iQY and Abs measurements showed a maximum for this higher energy value (Fig. S14). iQY and Abs are consistently higher for $\lambda_{\mathrm{exc}}=305 \mathrm{~nm}$, and follow the same trends when $\mathrm{T}_{\mathrm{Ca}}$ is varied, regardless of the excitation wavelength. 

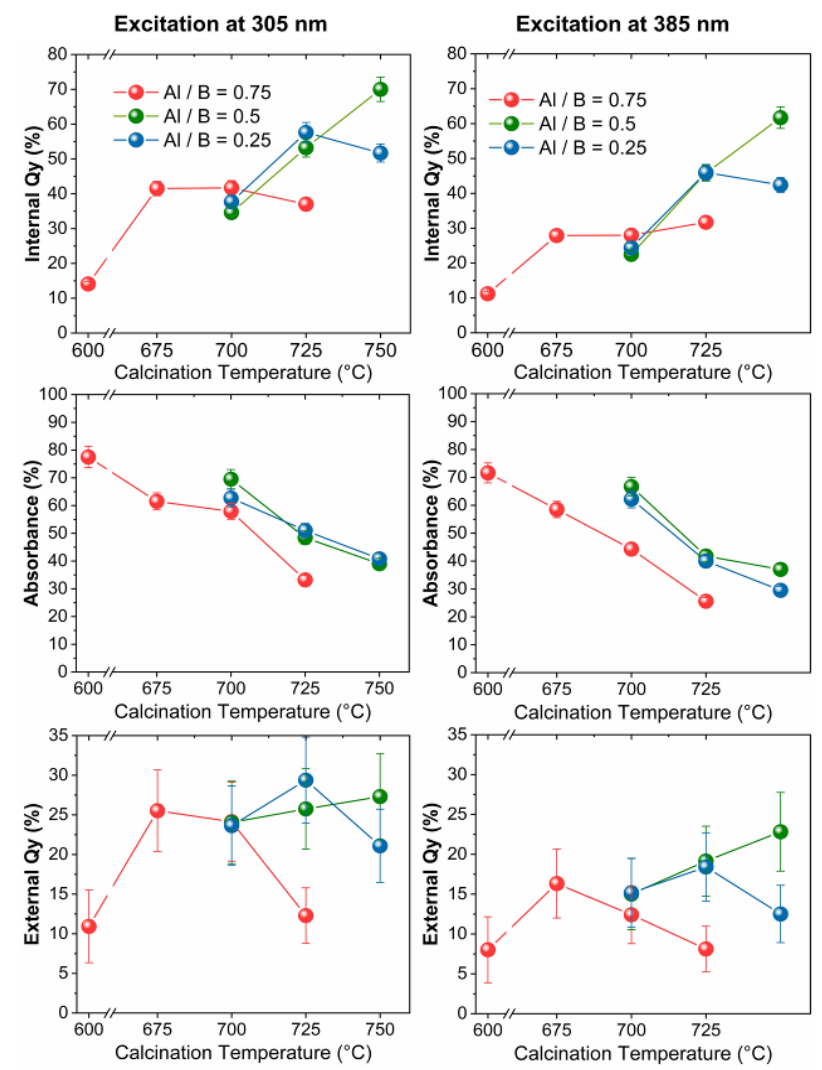

Fig. 5 Internal quantum yield (iQY), optical absorbance (Abs), and external quantum yield (eQY) of the most luminescent $\mathrm{ZAB}$ particles with the $\mathrm{Al} / \mathrm{B}$ ratios of $0.75,0.5$, and 0.25 , and $T_{C a}$ in the range of 600 to $750^{\circ} \mathrm{C}$. The phosphors with $T_{C a}$ leading to poor PL quality due to black carbon are not shown.

iQY increases by raising $\mathrm{T}_{\mathrm{Ca}}$ and then stabilizes or even decreases slightly. Abs decreases from more than $75 \%$ for $\mathrm{T}_{\mathrm{Ca}}=600{ }^{\circ} \mathrm{C}$, to less than $40 \%$ for $\mathrm{T}_{\mathrm{Ca}}=750{ }^{\circ} \mathrm{C}$. Consequently, the external quantum yields (eQY) shows a maximum for $\mathrm{T}_{\mathrm{Ca}}$ ranging from $675^{\circ} \mathrm{C}$ to $750^{\circ} \mathrm{C}$ depending on the $\mathrm{Al} / \mathrm{B}$ ratio. The increase in $\mathrm{iQY}$ by raising $\mathrm{T}_{\mathrm{Ca}}$ is attributed to the gradual loss of black carbon clusters in the glassy ZAB matrix, as shown in Fig. 1, Fig. S2 and S3. Black carbon is a strong absorber of visible and NUV light. It therefore absorbs, without radiative relaxation, both NUV photons, which would otherwise excite the emitters, and the visible photons from the PL - i.e. from the relaxation of exited emitters.

The decrease in the Abs by raising $\mathrm{T}_{\mathrm{Ca}}$ basically has two main causes. First, similarly to the evolution of iQY, when black carbon is oxidized during the calcination step, it no longer absorbs NUV photons that would otherwise excite the emitters. The lower $\mathrm{Abs}$ value recorded for the $\mathrm{Al} / \mathrm{B}=0.75$ is consistent with an earlier release of trapped carbon shown in Fig. S2. Secondly, the origin of the 
luminescence is attributed to molecular emitters (see next section), which are very likely also oxidised further by raising $\mathrm{T}_{\mathrm{Ca}}$, resulting in the loss of photoluminescence. Finally, the similar PL, iQY and Abs of ZAB phosphors with the $\mathrm{Al} / \mathrm{B}$ ratios of 0.25 and 0.5 are consistent with their similar structural properties.

To conclude, internal and external QY as well as trichromatic coordinates of elaborated ZAB powders are presented in Table S1 and show that they are suitable for pc-WLED in the single phosphor configuration. Boron-rich phosphors (i.e. $\mathrm{Al} / \mathrm{B}=0.5-0.25$ ) are more efficient than Al-rich ones, with both the best compromise between a high eQY and a warm colour temperature obtained for $\mathrm{T}_{\mathrm{Ca}}=$ $700^{\circ} \mathrm{C}$, and the most efficient cold-white emissions for $\mathrm{T}_{\mathrm{Ca}}=725^{\circ} \mathrm{C}$, having a high iQY of $49 \%$ when excited at $385 \mathrm{~nm}$. If the iQY values of $50 \%$ is nowadays regularly reached in top-tier carbon-based phosphors emitting blueish light, ${ }^{52-54}$ it is particularly high for white-emitting phosphors. ${ }^{55}$ While the excitation of ZAB phosphors at $305 \mathrm{~nm}$ offers even higher QYs, it however leads to a very bluish emission, as shown in Fig. S15, due to the excitation-dependent emission mechanisms described in the next section. Moreover, technically, the loss in eQY at higher excitation wavelengths in the NUV would be compensated by the higher efficiency of the current LEDs emitting at $385 \mathrm{~nm}$ compared to those emitting at $305 \mathrm{~nm}$.

\section{Photoluminescence excitation}

A detailed investigation of the PL excitation of ZAB phosphors is presented here, providing new insights into the molecular origin of PL. Indeed, if the emission of polycyclic aromatic hydrocarbon molecules have clearly been observed in YAB phosphor synthesized by sol-gel methods, ${ }^{32}$ the molecular origin of the PL of YAB phosphors by the PP method has only been suggested from timeresolved PL studies. ${ }^{56}$ The PL spectra of ZAB phosphors with the $\mathrm{Al} / \mathrm{B}$ ratios of 0.75 and 0.5 , recorded for excitations ranging from 250 to $550 \mathrm{~nm}$ have been compiled to form excitation-emission maps as shown in Fig. 6. The overall $\mathrm{T}_{\mathrm{Ca}}$-dependent behaviour of the $\mathrm{PL}$ is in good agreement with Fig. 4, with a shift of the emission band towards shorter wavelengths (i.e. blue shift), for all excitation wavelengths. We can also observe the strong effect of the chemical composition on the PL properties, as the increase in the $\mathrm{Al} / \mathrm{B}$ ratio of $\mathrm{ZAB}$ phosphors for a given $\mathrm{T}_{\mathrm{Ca}}$ of 700 and $725^{\circ} \mathrm{C}$ causes a strong 
blue shift in PL spectra, for all excitation wavelengths. Consistently, excitation-emission maps of ZAB phosphors with the $\mathrm{Al} / \mathrm{B}$ ratio of 0.25 (shown in Fig. S16) are very similar to that of 0.5 . It should be noted that the $\mathrm{ZAB}$ can be efficiently excited in a wide wavelength range compatible with $\mathrm{UV}$ and blue commercial LED.
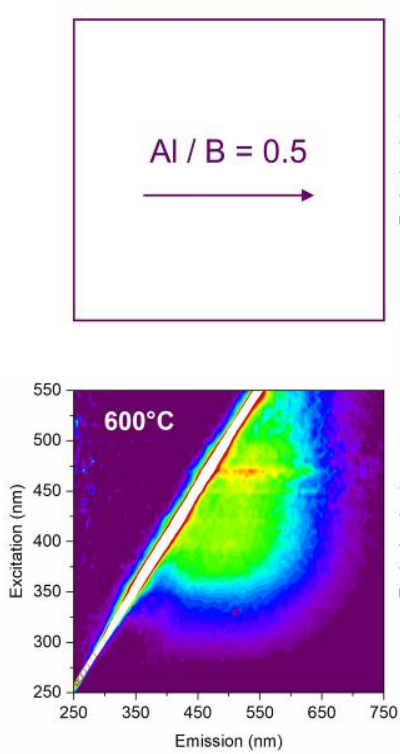
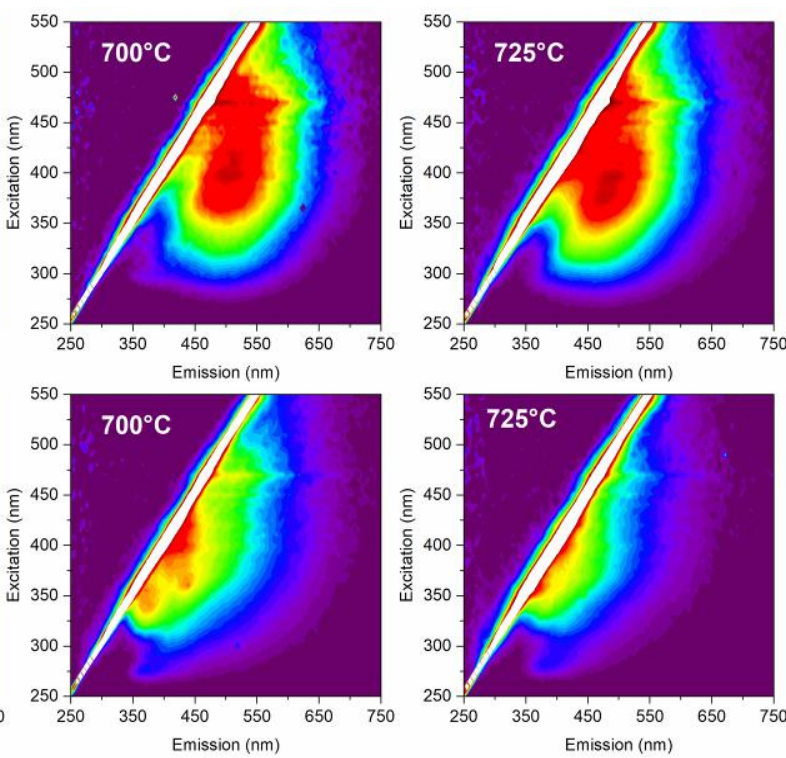
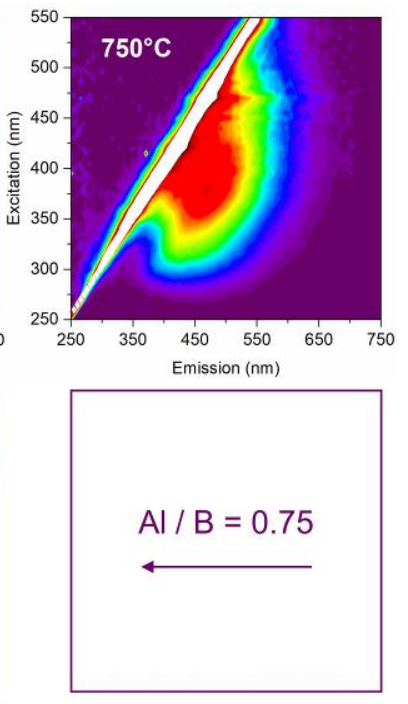

Fig. 6 Excitation-emission maps of ZAB phosphors with the $A l / B$ ratio of 0.5 and 0.75 , and calcination temperature in the range of 700 to $750^{\circ} \mathrm{C}$ and 600 to $725^{\circ} \mathrm{C}$, respectively. The emission spectra were recorded for excitation with a step of $5 \mathrm{~nm}$, from 250 to $550 \mathrm{~nm}$. Relative intensities are indicated by a rainbow coloured map, with red being the most intense, and dark purple the least intense, to show the variation in emission for each $\lambda_{\text {exc }}$. The higher intensities for excitation at 450 and $470 \mathrm{~nm}$ are measurement artefacts.

Interestingly, these excitation-emission maps show an excitation-dependent emission for all phosphors, typically observed in small graphene oxide derivatives (GODs) and larger carbon nanodots (CNDs). ${ }^{57}$ This feature is attributed to the presence of many different GODs / CNDs, having each different radiative energy states. Thus, the set of excited GODs / CNDs varies with the excitation wavelength, and the PL spectra varies accordingly. This diversity of energy states in GODs / CNDs is classically attributed to their size: due to quantum confinement, a small sized GODs / CNDs has a wide energy gap and vice versa. ${ }^{55,58,59}$ Therefore it is often argued that excitation-dependent emission is a signature of a polydispersity of GODs / CNDs size. 
If luminescent molecular species are primarily suspected in the case of ZAB phosphors, the analogy with GODs / CNDs is supported by recent results showing the molecular origin of the PL in GODs / CNDs synthesised by chemical methods. ${ }^{60-63}$ Thus, the measured excitation-dependent emission may also indicate a broad distribution of luminescent molecular species, and the blue shift of the PL with increasing $\mathrm{T}_{\mathrm{Ca}}$ could be attributed to the degradation of luminescent molecular species with a small energy gap (larger entities), favouring the wide energy gap ones (smaller entities). Accordingly, in Fig.6, the emission for excitation in the range of $500-550 \mathrm{~nm}$, ascribed to luminescent molecular species with a small energy gap, vanishes as $\mathrm{T}_{\mathrm{Ca}}$ is raised. Overall, the blue shift of the emission band of ZAB phosphor is systematically associated with a loss of carbon, which is either due to an increase in $\mathrm{T}_{\mathrm{Ca}}$ (fig. $\mathrm{S} 3$ ) or to an increase in the $\mathrm{Al} / \mathrm{B}$ ratio of $\mathrm{ZAB}$ particles that traps less carbon (Fig. S2) due to a more open amorphous network. During the calcination, larger carbonaceous species characterized by small energy gaps would be more fragile and sensitive to degradation, especially when the amorphous matrix is less dense. Finally it should be noted that the broad emitting phosphors exhibit a lower excitation-dependent emission effect. We attribute this to the reabsorption of most energetic emissions ( 350 to $450 \mathrm{~nm}$ ) by molecular emitter with small energy gaps.

Eventually, calibrated room-temperature PLE spectra of phosphors with the $\mathrm{Al} / \mathrm{B}$ ratios of 0.5 and 0.75 are shown in Fig. 7, for calcination at 700 and $750{ }^{\circ} \mathrm{C}$, and at 600 and $700{ }^{\circ} \mathrm{C}$, respectively. The excitation profiles were recorded for $\lambda_{\mathrm{em}}=500 \mathrm{~nm}$, i.e. $20000 \mathrm{~cm}^{-1}$. For both compositions, a very broad excitation signal was obtained, deconvoluted into three Gaussian functions centred around 25100, 28500, and $31600 \mathrm{~cm}^{-1}(400,350$ and $316 \mathrm{~nm})$. These excitation profiles further evidence the existence of several emitting centres, located in various local environments ${ }^{64}$ due to the amorphous network. Such multi-excitation states together with an excitation-dependent emission have been observed in carbon dots prepared by hydrothermal synthesis, and also attributed to the presence of several different luminescent molecular species. ${ }^{61-63}$ 

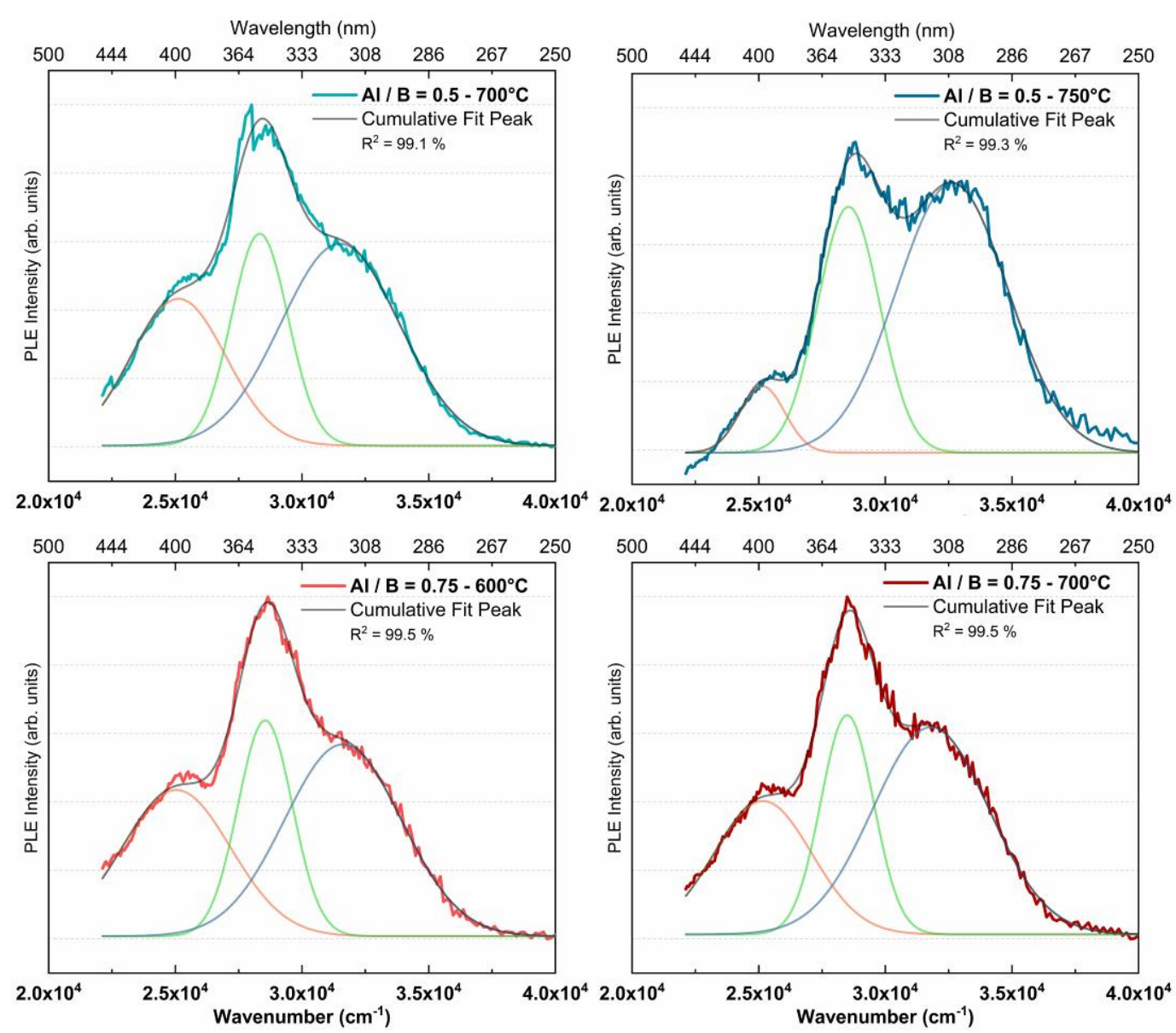

Fig. 7 PLE spectra of ZAB phosphors with $A l / B$ ratio of 0.5 and 0.75 , and calcinated at the temperature of 700 and $750{ }^{\circ} \mathrm{C}$, and 600 and $700{ }^{\circ} \mathrm{C}$, respectively. The spectra were fitted with three Gaussian functions as a function of the energy, and corresponding wavelength indicated.

For both compositions, the increase in $\mathrm{T}_{\mathrm{Ca}}$ results in a decrease in the low-energy excitation at $25100 \mathrm{~cm}^{-1}(0.63 \mathrm{eV})$, to the favour of high-energy excitation at $31600 \mathrm{~cm}^{-1}(1.44 \mathrm{eV})$, in particular for the phosphors with the $\mathrm{Al} / \mathrm{B}$ ratio of 0.5 (Table S3). This modification of the excitation supports the hypothesis of the degradation of large luminescent molecular species with small energy gap, to the favour of smaller luminescent molecular species with larger energy gap. Finally, despite a $100{ }^{\circ} \mathrm{C}$ difference in $\mathrm{T}_{\mathrm{Ca}}$, excitation spectra (Fig. 7) and excitation-emission maps (Fig. 6) of ZAB phosphors with $\mathrm{Al} / \mathrm{B}=0.5, \mathrm{~T}_{\mathrm{Ca}}=700^{\circ} \mathrm{C}$ and $\mathrm{Al} / \mathrm{B}=0.75, \mathrm{~T}_{\mathrm{Ca}}=600^{\circ} \mathrm{C}$ appear similar, suggesting that a boronrich matrix not only traps carbon more strongly, but also preserves the small energy gap emitting species (i.e. large luminescent molecular species) at higher temperature. 
It should be noted here that the only attribution of the optical shifts to the size of the luminescent molecular species is a simplification, as their stacking ${ }^{65}$, surface states ${ }^{66}$, and local environment ${ }^{64}$, also affecting their optical transitions, can be modified during the calcination process. The three Gaussian functions fit does not represent only three optically active luminescent molecular species, but rather many, separated into three energy gap ranges.

Alternatively, the high-energy excitation at $31600 \mathrm{~cm}^{-1}$ could be attributed to defects in the matrix, that excite luminescent molecular species, responsible for the warmer part of the PL spectra. This combination has been observed by Gan et al. in the case of graphene oxide prepared by the Hummers method. ${ }^{67}$

Those results further support the hypothesis of the presence of luminescent molecular species trapped in the micrometric amorphous $\mathrm{ZAB}$ and $\mathrm{YAB}$ particles, although their clear identification has so far been lacking. 


\section{CONCLUSIONS}

The PP method has been used to synthesize ZAB phosphors, successfully substituting the yttrium cation by zinc cation in well-described YAB phosphors. The composition has been optimized for a given $\mathrm{ZnO}$ molar content of $12 \%$, and by varying the $\mathrm{Al} / \mathrm{B}$ ratio ranging from 0.25 to 0.75 , leading to strongly luminescent powders with broad emission and excitation spectra.

The luminescence appears as the black carbon (strong absorber in the visible) inside the particles is gradually removed during calcination, then shifts from yellowish to bluish by raising the calcination temperature, and eventually disappears gradually between 725 and $800{ }^{\circ} \mathrm{C}$, as the luminescent molecular species are finally decomposed (oxidized) during the matrix crystallization.

The excitation-dependant behaviour of the photoluminescence, as well as the broad excitation band demonstrate a large amount of radiative energy levels, attributed to a wide variety of molecular luminescent species trapped during their formation in the amorphous matrix of ZAB particles upon calcination. The blue shift of the PL by raising the calcination temperature is attributed to the modification of the nature or distribution of such carbon-based luminescent species, resulting in an increase in the mean energy of the optical transitions. Modifying the $\mathrm{Al} / \mathrm{B}$ ratio during synthesis results in a strong modification of the morphology and microstructure of ZAB particles. In particular, carbonaceous species are more strongly trapped in the ZAB matrix when the boron content is increased due to a denser packing of the amorphous network. This leads to a red shift of the PL, suggesting that large luminescent molecular species with smaller energy gap are preserved.

It should be noted that without optimization of light absorption and extraction, the eQY values are still high, ranging from 15 to $25 \%$ depending on the excitation wavelength. Given the low cost of the precursors and the up-scalable synthesis, we believe that further device optimization would result in competitive rare-earth-free phosphors suitable for NUV-LEDs based devices.

These findings report the impact of the microstructure on luminescence of metal borates, which can be applied to engineer other inorganic oxide fabricated by the PP method, provided they can maintain an amorphous structure up to a high enough temperature so the black carbon is removed, while having a dense network to trap luminescent molecular species. 


\section{CONFLICTS OF INTEREST}

There are no conflicts to declare.

\section{ACKNOWLEDGMENTS}

P. G. held a doctoral fellowship from the CDP Eco-SESA CDP Eco-SESA receiving fund from the French National Research Agency in the framework of the "Investissements d'avenir" program (ANR15-IDEX-02). The authors further acknowledge the facilities, and the scientific and technical assistance of the CMTC characterization platform of Grenoble INP, which is supported by the Centre of Excellence of Multifunctional Architectured Materials (LabEx CEMAM) under the contract ANR10-LABX-44-01 funded by the "Investments for the Future" Program. This research was also funded by Institut Carnot "Energies du Futur" through the "ECOLED" project.

\section{NOTES AND REFERENCES}

1 S. Nakamura and M. R. Krames, Proc. IEEE, 2013, 101, 2211-2220.

2 J. Y. Tsao, M. H. Crawford, M. E. Coltrin, A. J. Fischer, D. D. Koleske, G. S. Subramania, G. T. Wang, J. J. Wierer and R. F. Karlicek, Adv. Opt. Mater., 2014, 2, 809-836.

3 J. Cho, J. H. Park, J. K. Kim and E. F. Schubert, Laser Photonics Rev., 2017, 11, 1600147.

4 N. C. George, A. J. Pell, G. Dantelle, K. Page, A. Llobet, M. Balasubramanian, G. Pintacuda, B. F. Chmelka and R. Seshadri, Chem. Mater., 2013, 25, 3979-3995.

5 X. Qin, X. Liu, W. Huang, M. Bettinelli and X. Liu, Chem. Rev., 2017, 117, 4488-4527.

6 European Commission, Study on the review of the list of critical raw materials, 2017.

7 U. S. Geological Survey, in Mineral Commodity Summaries, 2019, p. 200p.

8 D. Chiriu, L. Stagi, C. M. Carbonaro and P. C. Ricci, Phys. Status Solidi Curr. Top. Solid State Phys., 2016, 13, 989-997.

9 C. C. Pavel, A. Marmier, E. Tzimas, T. Schleicher, D. Schüler, M. Buchert and D. Blagoeva, Phys. Status Solidi Appl. Mater. Sci., 2016, 213, 2937-2946.

10 P. F. Smet, A. B. Parmentier and D. Poelman, J. Electrochem. Soc., 2011, 158, R37.

11 M. Shang, C. Li and J. Lin, Chem. Soc. Rev., 2014, 43, 1372-1386.

12 Y. Zhuo, A. Mansouri Tehrani, A. O. Oliynyk, A. C. Duke and J. Brgoch, Nat. Commun., 2018, 9, 1-10.

13 A. A. Bol, R. Van Beek and A. Meijerink, Chem. Mater., 2002, 14, 1121-1126.

14 C. Zhang and J. Lin, Chem. Soc. Rev., 2012, 41, 7938-7961.

15 W. H. Green, K. P. Le, J. Grey, T. T. Au and M. J. Sailor, Science (80-. )., 1997, 276, 1826-1828.

16 V. Bekiari and P. Lianos, Langmuir, 1998, 14, 3459-3461.

17 C. K. Lin, Y. Luo, H. You, Z. Quan, J. Zhang, J. Fang and J. Lin, Chem. Mater., 2006, 18, 458-464.

18 H. MASAI, J. Ceram. Soc. Japan, 2013, 121, 150-155.

19 F. Gu, S. F. Wang, M. K. Lü, G. J. Zhou, D. Xu and D. R. Yuan, J. Phys. Chem. B, 2004, 108, 81198123. 
M. Anicete-Santos, F. C. Picon, M. T. Escote, E. R. Leite, P. S. Pizani, J. A. Varela and E. Longo, Appl. Phys. Lett., 2006, 88, 211911-211914.

C. Lin, M. Yu, Z. Cheng, C. Zhang, Q. Meng and J. Lin, Inorg. Chem., 2008, 47, 49-55.

L. S. Cavalcante, J. C. Sczancoski, J. W. M. Espinosa, V. R. Mastelaro, A. Michalowicz, P. S. Pizani, F. S. De Vicente, M. S. Li, J. A. Varela and E. Longo, J. Alloys Compd., 2009, 471, 253-258.

N. Chouhan, C. C. Lin, S. F. Hu and R. S. Liu, J. Mater. Chem. C, 2015, 3, 1473-1479.

Y. Kaihatsu, W. N. Wang, F. Iskandar and K. Okuyama, Mater. Lett., 2010, 64, 836-839.

T. Hasegawa, Y. Abe, A. Koizumi, T. Ueda, K. Toda and M. Sato, Inorg. Chem., 2018, 57, 857-866.

X. Zhang, Z. Lu, H. Liu, J. Lin, X. Xu, F. Meng and C. Tang, J.Mater.Chem.C, 2015, 3, 3311-3317.

W. N. Wang, T. Ogi, Y. Kaihatsu, F. Iskandar and K. Okuyama, J. Mater. Chem., 2011, 21, 5183-5189.

T. Ogi, Y. Kaihatsu, F. Iskandar, W. N. Wang and K. Okuyama, Adv. Mater., 2008, 20, 3235-3238.

S. N. Baker and G. A. Baker, Angew. Chemie - Int. Ed., 2010, 49, 6726-6744.

Ferrier, B. Viana and A. Ibanez, J. Mater. Chem. C, 2015, 3, 5795-5802.

A. Ibanez, J. Lumin., 2017, 188, 448-453.

P. Burner, A. D. Sontakke, M. Salaün, M. Bardet, J. M. Mouesca, S. Gambarelli, A. L. Barra, A. Ferrier,

B. Viana, A. Ibanez, V. Maurel and I. Gautier-Luneau, Angew. Chemie - Int. Ed., 2017, 56, 1399513998.

P. P. Neves, L. J. Q. Maia, M. I. B. Bernardi, A. R. Zanatta, V. R. Mastelaro, S. M. Zanetti and E. R. Leite, J. Sol-Gel Sci. Technol., 2004, 29, 89-96.

K. Nose and M. Zenki, Analyst, 1991, 116, 711-714.

V. F. Guimarães, M. Salaün, P. Burner, L. J. Q. Maia, A. Ferrier, B. Viana, I. Gautier-Luneau and A. Ibanez, Solid State Sci., 2017, 65, 6-14.

J. Lin, M. Yu, C. Lin and X. Liu, J. Phys. Chem. C, 2007, 111, 5835-5845.

G. E. Brown, F. Farges and G. Calas, Rev. miner., 1995, 32, 317-410.

A. Nukui, U. Shimizugawa, S. Inoue, H. Ozawa, R. Uno, K. Oosumi and A. Makishima, J. Non. Cryst. Solids, 1992, 150, 376-379.

A. Dietzel, Glasstruktur und Glaseigenschaften, Glastechn. Ber. 22, 1948.

T. Jawhari, A. Roid and J. Casado, Carbon N. Y., 1995, 33, 1561-1565.

A. Merlen, J. G. Buijnsters and C. Pardanaud, A guide to and review of the use of multiwavelength Raman spectroscopy for characterizing defective aromatic carbon solids: From graphene to amorphous carbons, 2017, vol. 7.

A. Ferrari and J. Robertson, Phys. Rev. B - Condens. Matter Mater. Phys., 2000, 61, 14095-14107. V. F. Guimarães, P. Burner, L. J. Q. Maia, A. Ferrier, B. Viana, I. Gautier-Luneau and A. Ibanez, Proc. SPIE, 2016, 9749, 97490B.

E. M. Elssfah, C. C. Tang, J. Zhang, H. S. Song, X. X. Ding and S. R. Qi, Mater. Res. Bull., 2007, 42, $482-486$.

T. Ogi, H. Iwasaki, A. B. D. Nandiyanto, F. Iskandar, W. N. Wang and K. Okuyama, J. Mater. Chem. C, 2014, 2, 4297-4303. 
K. Januchta, R. E. Youngman, A. Goel, M. Bauchy, S. J. Rzoska, M. Bockowski and M. M. Smedskjaer, J. Non. Cryst. Solids, 2017, 460, 54-65. N. Mascaraque, K. Januchta, K. F. Frederiksen, R. E. Youngman, M. Bauchy and M. M. Smedskjaer, J. Am. Ceram. Soc., 2019, 102, 1157-1168.

A. A. Osipov, V. E. Eremyashev, A. S. Mazur, P. M. Tolstoi and L. M. Osipova, Glas. Phys. Chem., 2016, 42, 230-237.

C. Zhu, X. Nai, D. Zhu, F. Guo, Y. Zhang and W. Li, J. Solid State Chem., 2013, 197, 1-6.

Å. Johan, S. Göran and G. Jekabs, Acta Chem. Scand., 1997, 51, 1045-1050.

K. L. Wong, J. C. G. Bünzli and P. A. Tanner, J. Lumin., 2020, 224, 117256.

F. Ehrat, S. Bhattacharyya, J. Schneider, A. Löf, R. Wyrwich, A. L. Rogach, J. K. Stolarczyk, A. S. Urban and J. Feldmann, Nano Lett., 2017, 17, 7710-7716.

D. Wang, Z. Wang, Q. Zhan, Y. Pu, J. X. Wang, N. R. Foster and L. Dai, Engineering, 2017, 3, 402408.

D. Qu, M. Zheng, L. Zhang, H. Zhao, Z. Xie, X. Jing, R. E. Haddad, H. Fan and Z. Sun, Sci. Rep., 2014, 4, $1-11$.

X. Guo, C. F. Wang, Z. Y. Yu, L. Chen and S. Chen, Chem. Commun., 2012, 48, 2692-2694.

A. D. Sontakke, A. Ferrier, P. Burner, V. F. Guimarães, M. Salaün, V. Maurel, I. Gautier-Luneau, A. Ibanez and B. Viana, J. Phys. Chem. Lett., 2017, 8, 4735-4739.

Z. Gan, H. Xu and Y. Hao, Nanoscale, 2016, 8, 7794-7807.

H. Li, X. He, Z. Kang, H. Huang, Y. Liu, J. Liu, S. Lian, C. H. A. Tsang, X. Yang and S. T. Lee, Angew. Chemie - Int. Ed., 2010, 49, 4430-4434.

C. Russo, B. Apicella and A. Ciajolo, Sci. Rep., 2019, 9, 14566.

L. Shi, J. H. Yang, H. B. Zeng, Y. M. Chen, S. C. Yang, C. Wu, H. Zeng, O. Yoshihito and Q. Zhang, Nanoscale, 2016, 8, 14374-14378.

M. Fu, F. Ehrat, Y. Wang, K. Z. Milowska, C. Reckmeier, A. L. Rogach, J. K. Stolarczyk, A. S. Urban and J. Feldmann, Nano Lett., 2015, 15, 6030-6035.

62 S. Bhattacharyya, F. Ehrat, P. Urban, R. Teves, R. Wyrwich, M. Döblinger, J. Feldmann, A. S. Urban and J. K. Stolarczyk, Nat. Commun., 2017, 8, 1-9.

63 C. M. Carbonaro, D. Chiriu, L. Stagi, M. F. Casula, S. V Thakkar, L. Malfatti, K. Suzuki, P. C. Ricci and R. Corpino, J. Phys. Chem. C, 2018, 122, 25638-25650.

S. Park, E. K. Ji, H. K. Se, J. Seo, K. Chung, S. Y. Park, D. J. Jang, B. M. Medina, J. Gierschner and Y. P. Soo, J. Am. Chem. Soc., 2009, 131, 14043-14049.

M. Baroncini, G. Bergamini and P. Ceroni, Chem. Commun., 2017, 53, 2081-2093.

66 H. Ding, S. B. Yu, J. S. Wei and H. M. Xiong, ACS Nano, 2016, 10, 484-491.

67 Z. Gan, S. Xiong, X. Wu, T. Xu, X. Zhu, X. Gan, J. Guo, J. Shen, L. Sun and P. K. Chu, Adv. Opt. Mater., 2013, 1, 926-932. 